\title{
De novo Thrombotic Microangiopathy Induced by Cytomegalovirus Infection Leading to Renal Allograft Loss
}

\author{
Kristel De Keyzer Steven Van Laecke Patrick Peeters Raymond Vanholder
}

Renal Division, Ghent University Hospital, Ghent, Belgium

\section{Key Words}

Cytomegalovirus infection - Hemolytic-uremic syndrome • Kidney transplantation - Thrombotic microangiopathy

\begin{abstract}
After kidney transplantation, thrombotic microangiopathy (TMA) can occur de novo or as recurrent disease. Risk factors for de novo posttransplant TMA include ischemia-reperfusion injury, immunosuppressive drugs, viral infections, acute humoral rejection, and complement gene abnormalities. Cytomegalovirus infection as a trigger for posttransplant TMA in kidney transplant recipients has only been reported in 7 cases, all of them between 4 weeks and 8 years after transplantation. We describe a new case of de novo TMA in association with cytomegalovirus infection 25 years after kidney transplantation.

Copyright $\odot 2010$ S. Karger AG, Base
\end{abstract}

\section{Introduction}

Thrombotic microangiopathy (TMA) is a microvascular occlusive disorder defined by characteristic histopathological findings: thickening of arterioles and capillaries, endothelial swelling and detachment, subendothelial accumulation of proteins and cell debris, widening of the subendothelial space, platelet thrombi obstructing the lumina of the vessels, and fragmented red blood cells in the vessels or the interstitium (fig. 1) [1-7]. When the lesions predominate in the renal microvasculature, and the triad of microangiopathic hemolytic anemia, thrombocytopenia and acute renal failure is present, it is known as the hemolytic-uremic syndrome (HUS) [1-3, 6-12].

The majority of cases (approximately 90\%) are classified as typical HUS caused by an infection with Shiga-like toxin producing bacteria (enterohemorrhagic Escherichia coli, Shigella dysenteriae type 1, or Citrobacter freundii) $[1,2,4-7,9,12,13]$ or an invasive infection with Streptococcus pneumoniae $[1,6,12,13]$. The remaining $10 \%$ are cases of atypical HUS (aHUS), which has a less favorable prognosis with death rates up to $25 \%$ and progression to Chronic Kidney Disease stage 5 (CKD5) in 50\% of patients [5-7]. aHUS can be classified into a familial variant (in less than $20 \%$ of cases) and a sporadic variant $[1,4,6$, 7]. The sporadic variant can be triggered by organ transplantation, malignancy, pregnancy, systemic lupus erythematosus, antiphospholipid syndrome, infection with the human immunodeficiency virus, and the use of quinine, oral contraceptive drugs, anticancer drugs, bevacizumab, antiplatelet drugs, and immunosuppressive drugs $[1,4,6,8,9,12,13]$. However, half of the sporadic cases appear to be idiopathic $[4,6]$.

\section{KARGER}

Fax +41613061234 E-Mail karger@karger.ch www.karger.com
(C) 2010 S. Karger AG, Basel

0250-8095/10/0325-0491\$26.00/0

Accessible online at:

www.karger.com/ajn
Dr. Kristel De Keyzer

Renal Division, Ghent University Hospital

De Pintelaan 185

BE-9000 Gent (Belgium)

Tel. +32 93324 509, Fax +3293324 599, E-Mail kristel.dekeyzer@ mail.be 

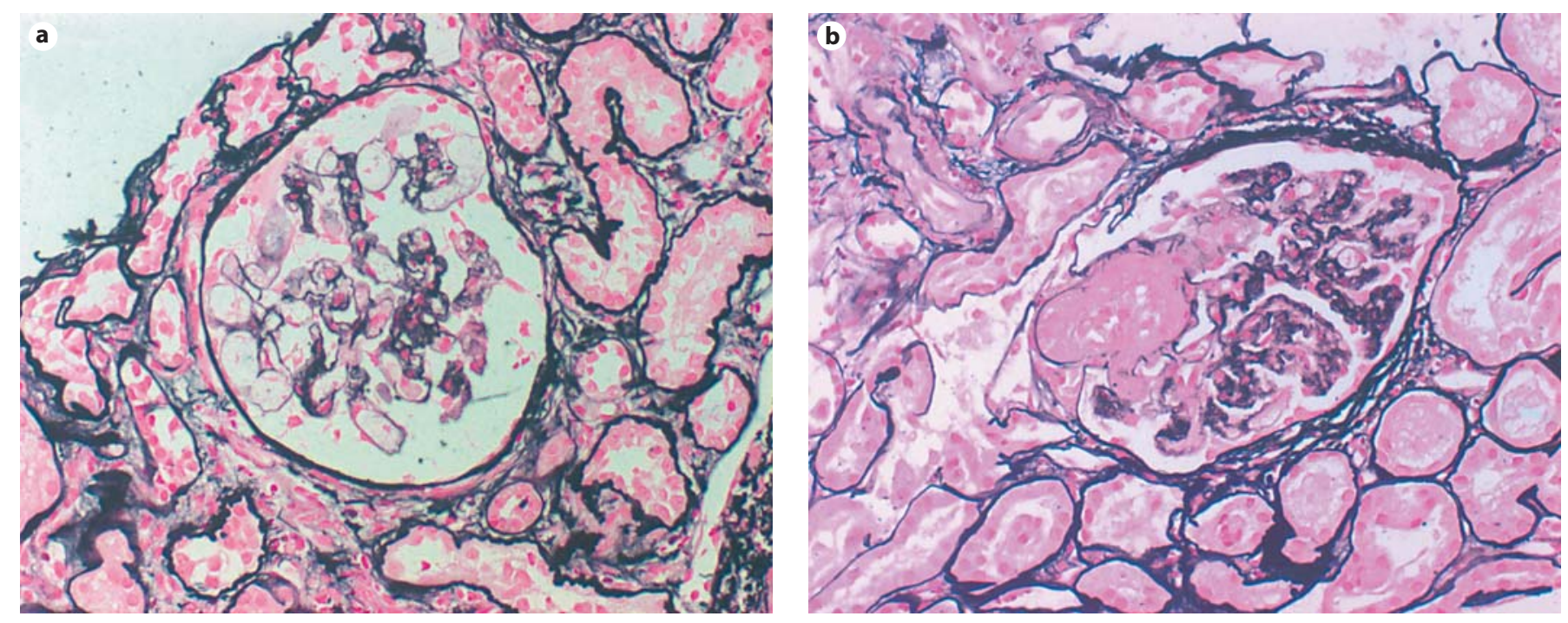

Fig. 1. Renal allograft with CMV-induced posttransplant TMA shows dilated capillary loops with thinning of the capillary walls and subendothelial fibrin deposits (a) and an obliterated lumen of the capillary loop by a thrombus (b). Methenamine-silver stain. Original magnification $\times 250$.

aHUS is linked to abnormal activation of the alternative complement pathway $[1,5-7,13]$. The complement system is part of the body's innate immune system and can be activated by three pathways: the classical, the alternative, and the lectin complement pathway. In all three pathways, a $\mathrm{C} 3$ convertase cleaves and activates $\mathrm{C} 3$, causing a cascade of further cleavage and activation events. Both membrane-anchored and fluid-phase complement regulatory proteins, such as factor $\mathrm{H}(\mathrm{CFH})$, factor I (CFI), membrane cofactor protein (MCP), and thrombomodulin (encoded by the THBD gene), control complement activation by favoring the inactivation of $\mathrm{C} 3 \mathrm{~b}$ and dissociating the $\mathrm{C} 3$ and $\mathrm{C} 5$ convertases $[4-7,13]$.

In $50-60 \%$ of cases of aHUS, complement gene abnormalities have been established $[6,12]$. In $40-50 \%$ of patients there are loss-of-function mutations in genes coding for the complement regulatory proteins, impairing the protection of endothelial cells from complement attack: $C F H$ mutations (20-30\%), CFI mutations (4-10\%), MCP mutations (10-15\%), and THBD mutations (5\%) [4$7,13]$. Anti-CFH autoantibodies causing functional $\mathrm{CFH}$ deficiency are found in 6-10\% [6, 7, 13]; most of these patients have a homozygous deletion of the genes for $\mathrm{CFH}$ related proteins 1 (CFHR1) and 3 (CFHR3) [6, 7]. CFHR1/3 deficiency itself also predisposes to aHUS [6]. A heterozygous CFH/CFHR1 hybrid gene is found in 3.5\% $[6,7]$. Other aHUS patients have gain-of-function mutations in genes for C3 (5-10\%) or factor B (CFB; 1-2\%), leading to a hyperactive $\mathrm{C} 3$ convertase resistant to inactivation [57]. Approximately $5 \%$ of patients with aHUS have combined mutations (e.g. $C F H$ with $C F I$ or $M C P$ ), or both mutations and anti-CFH autoantibodies $[6,7]$.

After kidney transplantation, TMA may occur for the first time (de novo posttransplant TMA) or recur in the allograft of patients who progressed to CKD5 because of HUS (recurrent posttransplant TMA) $[2-5,7,9]$. De novo posttransplant TMA has been reported in $0.8-14 \%$ of all kidney transplant recipients (KTRs) [3-6, 10]. It generally occurs in the early posttransplant period, but can develop years after transplantation $[4,5,7,10]$. It is usually triggered by acute humoral rejection, viral infections, or immunosuppressive drugs such as calcineurin inhibitors (CNI), mTOR inhibitors, antithymocyte globulin, and muromonab-CD3 $[2-8,10]$. A retrospective study found that 7 (29\%) of 24 KTRs with de novo posttransplant TMA carried mutations in $C F H$ and/or CFI, suggesting that genetic complement abnormalities are also important risk factors for de novo TMA [5, 7]. Posttransplant TMA has a variable clinical presentation $[2-5,8$, 10]. In general, anemia and thrombocytopenia are less severe than in native kidney TMA $[2,3,8,10]$, and extrarenal manifestations are rare [2-4]. Often delayed graft function or new dysfunction of the renal allograft is the only sign of posttransplant TMA [2-5, 7]. Since other conditions such as acute rejection can give a similar clinical picture, the diagnosis has to be confirmed by renal 
Table 1. Characteristics of the 8 patients with CMV-induced posttransplant TMA

\begin{tabular}{|c|c|c|c|c|c|c|c|c|}
\hline First author & $\begin{array}{l}\text { Age } \\
\text { years }\end{array}$ & Sex & $\begin{array}{l}\text { Interval } \\
\text { between } \\
\text { CMV and } \\
\text { TX }\end{array}$ & $\begin{array}{l}\text { Mani- } \\
\text { festation } \\
\text { of CMV } \\
\text { disease }\end{array}$ & $\begin{array}{l}\text { Interval } \\
\text { between } \\
\text { CMV and } \\
\text { TMA }\end{array}$ & $\begin{array}{l}\text { Posttrans- } \\
\text { plant } \\
\text { TMA }\end{array}$ & Treatment & Outcome \\
\hline Waiser [9] & 28 & M & 2 months & $\begin{array}{l}\text { CMV } \\
\text { esophagitis }\end{array}$ & 5 days & de novo & $\begin{array}{l}\text { IV ganciclovir } \\
+ \text { plasma exchange }\end{array}$ & $\begin{array}{l}\text { renal allograft loss } \\
\text { (return to hemodialysis) }\end{array}$ \\
\hline Waiser [9] & 33 & M & 8 years & $\begin{array}{l}\text { CMV } \\
\text { syndrome }\end{array}$ & 3 days & de novo & $\begin{array}{l}\text { IV ganciclovir } \\
+ \text { plasma exchange }\end{array}$ & $\begin{array}{l}\text { renal allograft loss } \\
\text { (explantation and return } \\
\text { to hemodialysis) }\end{array}$ \\
\hline $\begin{array}{l}\text { Karthikeyan } \\
{[10]}\end{array}$ & n.s. & n.s. & n.s. & $\begin{array}{l}\text { CMV } \\
\text { nephritis }\end{array}$ & n.s. & n.s. & $\begin{array}{l}\text { temporary } \\
\text { discontinuation of CNI } \\
+ \text { plasma exchange }\end{array}$ & n.s. \\
\hline Olie [11] & 8 & $\mathrm{~F}$ & 10 months & $\begin{array}{l}\text { CMV } \\
\text { syndrome }\end{array}$ & n.s. & $\begin{array}{l}\text { recurrent } \\
(\mathrm{CFH} \\
\text { mutation })\end{array}$ & $\begin{array}{l}\text { IV ganciclovir } \\
+ \text { plasma exchange } \\
\text { intensification }\end{array}$ & complete recovery \\
\hline Olie [11] & & & 17 months & $\begin{array}{l}\text { CMV } \\
\text { syndrome }\end{array}$ & 7 days & $\begin{array}{l}\text { recurrent } \\
(\mathrm{CFH} \\
\text { mutation })\end{array}$ & $\begin{array}{l}\text { IV ganciclovir } \\
+ \text { plasma exchange } \\
\text { intensification }\end{array}$ & complete recovery \\
\hline $\begin{array}{l}\text { Jeejeebhoy } \\
{[14]}\end{array}$ & 57 & $\mathrm{~F}$ & 6 weeks & $\begin{array}{l}\text { CMV } \\
\text { pneumonitis }\end{array}$ & n.s. & de novo & $\begin{array}{l}\text { temporary } \\
\text { discontinuation of } \mathrm{CNI} \\
+ \text { IV ganciclovir } \\
+ \text { plasma exchange }\end{array}$ & complete recovery \\
\hline Noël [15] & 39 & M & 29 days & n.s. & n.s. & de novo & n.s. & n.s. \\
\hline Noël [15] & 23 & M & 255 days & n.s. & n.s. & de novo & n.s. & n.s. \\
\hline Present case & 46 & M & 25 years & $\begin{array}{l}\text { CMV } \\
\text { syndrome }\end{array}$ & 8 days & de novo & $\begin{array}{l}\text { IV ganciclovir } \\
+ \text { IV foscarnet } \\
+ \text { plasma exchange }\end{array}$ & $\begin{array}{l}\text { renal allograft loss } \\
\text { (return to hemodialysis) }\end{array}$ \\
\hline
\end{tabular}

$\mathrm{TX}=$ Transplantation; n.s. $=$ not specified

allograft biopsy $[2-4,7,8]$. The outcome is often disappointing, with graft loss rates up to $57 \%$ in the acute episode $[3,7,10]$.

Infection with human cytomegalovirus (CMV) as a trigger for posttransplant TMA in KTRs has been reported in only 7 cases (table 1). All patients developed TMA between 4 weeks and 8 years after transplantation. We describe a new case of de novo TMA after kidney transplantation in association with CMV infection 25 years after transplantation.

\section{Case Report}

A 19-year-old Caucasian male was started on chronic hospital hemodialysis in September 1979 because of CKD5 secondary to agenesis of the left kidney and congenital hydroureteronephrosis of the right kidney. In September 1980 he received a kidney transplant from a deceased donor and simultaneously underwent nephrectomy of his native kidney. Transplantation was complicated by acute cellular rejection, successfully treated with corticosteroids and cyclophosphamide.

At the age of 46,25 years after transplantation, he presented to our clinic with fever of 4 weeks' duration. Treatment with moxifloxacin $400 \mathrm{mg} / \mathrm{day}$ had been initiated 4 days earlier because of a productive cough. He also experienced anorexia, nausea, and vomiting, and reported that his urine output had decreased over the preceding days. Apart from a known cardiac murmur the clinical examination was unremarkable. His maintenance therapy included azathioprine, prednisolone, alfacalcidol, calcium carbonate, and cimetidine.

Laboratory tests revealed acute renal allograft failure with a creatinine of $7.0 \mathrm{mg} / \mathrm{dl}$ compared to a baseline value of $1.1 \mathrm{mg} / \mathrm{dl}$, hyperphosphatemia, normokalemia, and hyponatremia. There was a mild pancytopenia with a hemoglobin of $10 \mathrm{~g} / \mathrm{dl}$, white blood cell count of $3,350 / \mu \mathrm{l}$ and platelet count of $116,000 / \mu \mathrm{l}$. Lac- 
tate dehydrogenase (LDH) was elevated (851 U/l) with normal haptoglobin in the absence of schistocytes. Both the direct and indirect antiglobulin Coombs' test were negative. The C-reactive protein was slightly elevated $(5.8 \mathrm{mg} / \mathrm{dl})$. Urinalysis revealed normal urine sediment but new onset proteinuria (1.1 g/g creatinine). Urine and blood cultures were negative. There were no pulmonary infiltrates on chest X-ray. A high-resolution computed tomography scan demonstrated mild bilateral pleural effusions with associated compression atelectasis. Ultrasound of the renal allograft and color Doppler ultrasound of the renal transplant artery and vein were normal. An urgent renal allograft biopsy revealed interstitial fibrosis and tubular atrophy grade 2 plus acute tubular necrosis.

Primary CMV infection was suspected. The CMV-DNA polymerase chain reaction (PCR) proved highly positive $(1,600,000$ copies/ml blood). Therapy with oral valganciclovir was initiated at a dose of $450 \mathrm{mg}$ every other day, adjusted for renal function.

Because of persistent nausea and vomiting an esophagogastroduodenoscopy was performed, revealing esophagitis and diffuse gastritis with several ulcerations. Biopsies were subsequently taken; staining for Helicobacter pylori and in situ hybridization for CMV-DNA were negative. Therapy with a proton pump inhibitor was initiated.

Initially there was a partial response with a decline in viral load (650,000 copies/ml blood) and creatinine $(4.6 \mathrm{mg} / \mathrm{dl})$ after 3 days of treatment with antivirals and intravenous (IV) fluids. After a few days, however, the clinical condition deteriorated again. Chest radiology revealed an increased interstitial pattern. Because of clinical suspicion of CMV pneumonitis a repeat highresolution computed tomography was performed, showing a marked increase in the bilateral pleural effusions but no pulmonary infiltrates or ground-glass opacities. Blood tests showed a drop in hemoglobin $(7.9 \mathrm{~g} / \mathrm{dl})$ and thrombocytes $(99,000 / \mu \mathrm{l})$, high LDH (840 U/l), completely suppressed haptoglobin, and the presence of schistocytes on peripheral blood smear. Creatinine had risen again to a value of $5.2 \mathrm{mg} / \mathrm{dl}$, and the patient developed peripheral edema. A repeat biopsy demonstrated the development of TMA without evidence of typical viral lesions (fig. 1).

A diagnosis of CMV-induced de novo posttransplant TMA was made. Treatment with daily plasma exchange was started, combined with the administration of CMV hyperimmunoglobulin (CMVIg) and continued valganciclovir. Nevertheless, there was a further deterioration of renal allograft function and hemodialysis was initiated. Oral valganciclovir was replaced by IV ganciclovir. A follow-up biopsy confirmed the persistence of TMA and absence of rejection.

Viral load remained high $(75,000$ copies/ml blood) despite therapy with IV ganciclovir and CMVIg. Dosage could not be increased because of ganciclovir-induced myelosuppression confirmed by bone marrow biopsy. IV foscarnet was added and 1 week later the CMV-DNA PCR became negative and remained negative thereafter. IV foscarnet was subsequently discontinued; CMVIg was stopped 5 days later and IV ganciclovir 12 days later. Oral valganciclovir was then restarted. After subsequent normalization of hemolytic parameters, plasma exchange was successfully discontinued with permanent hematological remission. Unfortunately, there was no recovery of renal allograft function and the patient remained on chronic hospital hemodialysis. Because of a substantial residual urine output, the allograft was left in situ until January 2009.
In February 2010 the patient received a second kidney transplant from a CMV-seronegative deceased donor. At this point, CMV IgG was $>15,000 \mathrm{U} / \mathrm{ml}$ and the CMV-DNA PCR was below the detection limit. He was treated with IV ganciclovir for 1 week and oral valganciclovir until 100 days after transplantation as CMV prophylaxis. The posttransplant period was uneventful.

\section{Discussion}

CMV is a ubiquitous herpesvirus that is transmitted through, among others, saliva, urine, sex, blood transfusion, solid-organ transplantation, or hematopoietic stem cell transplantation. After primary infection, CMV remains latent within the host. In the immunocompetent host, primary CMV infection is asymptomatic or manifests as a mononucleosis-like syndrome. In immunocompromised hosts, however, primary infection, reactivation, or reinfection generally causes CMV disease [16]. This can manifest as CMV syndrome (i.e. fever, malaise, neutropenia, and/or thrombocytopenia) or as tissue-invasive disease (e.g. pneumonitis, gastrointestinal disease, hepatitis, pancreatitis, encephalitis, chorioretinitis, myocarditis, nephritis, or cystitis) [16, 17]. CMV has also been associated with a multitude of indirect effects in KTRs, such as acute and chronic graft rejection [11, 16], and opportunistic infections [16].

Only a few cases of TMA induced by CMV infection in KTRs have been reported in the literature (table 1). Hochstetler et al. [8] observed that $42 \%$ of 21 kidney and kidney-pancreas transplant recipients who developed cyclosporine-associated TMA in the early posttransplant period developed anti-CMV IgM antibodies during the acute TMA episode. Waiser et al. [9] reported 2 KTRs with de novo TMA immediately after the onset of primary CMV disease. Both were treated with IV ganciclovir and plasma exchange; hemolysis stopped once CMVDNAemia became undetectable. Karthikeyan et al. [10] reported 29 KTRs with CNI-associated TMA of whom 1 had concomitant CMV disease. Olie et al. [11] described a patient with CKD5 due to familial aHUS with a $C F H$ mutation who was transplanted with continuous prophylactic plasma exchange. She had 2 successive recurrences of TMA: the first was associated with primary CMV infection 10 months after transplantation, the second with a relapse of CMV disease 7 months later. Both recurrences resolved with IV ganciclovir and plasma exchange intensification. Jeejeebhoy and Zaltzman [14] described a case of de novo TMA in association with primary CMV disease 6 weeks after kidney transplantation; the condition resolved shortly after initiation of IV ganciclovir. 
Noël et al. [15] published a case series of 14 KTRs with TMA attributed to cyclosporine; in 2 cases the TMA was presumably triggered by CMV infection.

In both our patient and the previously reported cases the course of disease with onset of TMA within days after onset of CMV disease and the disappearance of hemolysis after negativation of CMV-DNAemia is highly suggestive of a causative role of CMV in the development of posttransplant TMA. It is highly unlikely, in the present case, that the TMA would have been induced by the immunosuppression, to which the patient had been submitted for 25 years.

The pathogenesis of de novo posttransplant TMA is still not completely understood. Several mechanisms have been proposed for CNI: direct endothelial toxicity, vasoconstriction (activation of the sympathetic nervous system, increased synthesis of endothelin, inhibition of local prostacyclin and nitric oxide production), prothrombotic actions (increased thromboxane $\mathrm{A}_{2}$ synthesis and decreased prostacyclin synthesis), and antifibrinolytic actions (upregulation of plasminogen activator inhibitor) [2, $4,7,10,15]$. Transplantation itself induces endothelial activation due to the graft procedure and ischemia-reperfusion injury $[4,5,7,10]$. Acute rejection and posttransplant viral infections also cause endothelial lesions and subsequent complement activation $[4,5,7,10]$. CMV can directly damage the endothelial cells $[2,9,14]$, and can cause platelet adhesion to the microvascular wall by inducing the expression of endothelial adhesion molecules and the release of von Willebrand factor $[2,9,11]$. In patients with complement gene abnormalities or anti-CFH autoantibodies, endothelial activation triggered by any of the above factors is enhanced by excessive complement activation $[5,7]$. Overall, it seems that two or more factors that amplify each other's effects have to be present to cause TMA in KTRs $[4,5,7,10]$. It might be conceivable to screen for mutations in $C F H, M C P, C F I, C 3, C F B$ and $T H B D$, and to search for $C F H R$ deletions and for anti-CFH autoantibodies in KTRs at the first episode of de novo TMA [5, 7].

There are no controlled trials or guidelines on treatment of posttransplant TMA and the current management is based on case reports and case series. In general, treatment of de novo posttransplant TMA comprises the elimination of any precipitating factors, relief of symptoms, and plasma therapy when considered necessary $[1,2]$.

In patients with presumed CNI-associated TMA, treatment consists of reducing, changing, or (temporarily) withdrawing the CNI $[2-5,7,8,10]$. However, not all patients respond, and the risk of acute rejection increases
$[5,7,8]$. In the setting of de novo TMA due to viral infection, the outcome generally parallels the response to treatment of the underlying infection [2]. CMV disease in KTRs should be treated with either IV ganciclovir ( $5 \mathrm{mg} / \mathrm{kg}$ twice daily, adjusted for renal function) or oral valganciclovir $(900 \mathrm{mg}$ twice daily, adjusted for renal function) until CMV is no longer detectable. In case of suspected ganciclovir resistance, baseline immunosuppression should be reduced and ganciclovir dosage should be increased (up to $10 \mathrm{mg} / \mathrm{kg}$ twice daily for normal renal function). If infection persists or ganciclovir is not tolerated due to myelosuppression, as was the case in our patient, or to any other side effect, therapy should be switched to a combination of IV ganciclovir and IV foscarnet, or IV foscarnet alone [17].

It is uncertain whether plasma therapy is imperative in the treatment of posttransplant TMA. However, it is generally accepted that severe, systemic TMA should be treated with plasma therapy $[2,3,5,7,10]$. It should be initiated within $24 \mathrm{~h}$ after diagnosis. The first option is plasma exchange, with an exchange of 1.5 times the expected plasma volume, which correlates with $60-75 \mathrm{ml} / \mathrm{kg}$ body weight. The alternative is plasma infusion of $20-30 \mathrm{ml} / \mathrm{kg}$ body weight 3 times a week, with restrictions in oligoanuric patients because of the risk of volume overload $[1,6,12]$. Platelet count and serum LDH are the most reliable markers to monitor the response to plasma therapy [1]. Hematological remission is achieved when the platelet count remains $>150,000 / \mu$ l for 2 weeks without signs of hemolysis (i.e. stable hemoglobin levels, no fragmented red blood cells, and no elevated LDH); hematological relapse is defined as the return of microangiopathic hemolytic anemia and thrombocytopenia after a normalization for at least 2 weeks [12]. Treatment should be continued until remission is achieved $[1,10]$. When patients remain in a critical condition despite intensive medical treatment, explantation of the renal allograft is the last therapeutic option [10].

\section{Conclusion}

$\mathrm{CMV}$ is a ubiquitous herpesvirus that affects many KTRs. CMV infection can trigger both de novo and recurrent posttransplant TMA. This can occur early after kidney transplantation but also many years later. CMVinduced posttransplant TMA generally begins within days after onset of CMV disease. Immediate treatment with IV ganciclovir until CMV-DNAemia is no longer detectable in combination with plasma therapy will usually result in remission of TMA. 


\section{Acknowledgment}

We would like to thank Prof. Dr. M. Praet for providing the pictures of the renal allograft biopsy.

\section{Disclosure Statement}

No conflict of interest to declare.

\section{References}

1 Ruggenenti P, Noris M, Remuzzi G: Thrombotic microangiopathy, hemolytic uremic syndrome, and thrombotic thrombocytopenic purpura. Kidney Int 2001;60:831-846.

-2 Ruggenenti P: Post-transplant hemolyticuremic syndrome. Kidney Int 2002;62:10931104.

-3 Schwimmer J, Nadasdy TA, Spitalnik PF, Kaplan KL, Zand MS: De novo thrombotic microangiopathy in renal transplant recipients: a comparison of hemolytic uremic syndrome with localized renal thrombotic microangiopathy. Am J Kidney Dis 2003;41:471-479.

-4 Ponticelli C, Banfi G: Thrombotic microangiopathy after kidney transplantation. Transpl Int 2006;19:789-794.

$\checkmark 5$ Le Quintrec M, Lionet A, Kamar N, Karras A, Barbier S, Buchler M, Fakhouri F, Provost F, Fridman WH, Thervet E, Legendre C, Zuber J, Frémeaux-Bacchi V: Complement mutation-associated de novo thrombotic microangiopathy following kidney transplantation. Am J Transplant 2008;8:1694-1701.

-6 Noris M, Remuzzi G: Atypical hemolyticuremic syndrome. N Engl J Med 2009;361: 1676-1687.

7 Noris M, Remuzzi G: Thrombotic microangiopathy after kidney transplantation. Am J Transplant 2010;10:1517-1523.
8 Hochstetler LA, Flanigan MJ, Lager DJ: Transplant-associated thrombotic microangiopathy: the role of IgG administration as initial therapy. Am J Kidney Dis 1994;23: 444-450.

$\checkmark 9$ Waiser J, Budde K, Rudolph B, Ortner MA, Neumayer HH: De novo hemolytic uremic syndrome postrenal transplant after cytomegalovirus infection. Am J Kidney Dis 1999;34:556-560.

10 Karthikeyan V, Parasuraman R, Shah V, Vera E, Venkat KK: Outcome of plasma exchange therapy in thrombotic microangiopathy after renal transplantation. Am J Trans plant 2003;3:1289-1294.

-11 Olie KH, Goodship TH, Verlaak R, Florquin S, Groothoff JW, Strain L, Weening JJ, Davin JC: Posttransplantation cytomegalovirusinduced recurrence of atypical hemolytic syndrome associated with a factor $\mathrm{H}$ mutation: successful treatment with intensive plasma exchanges and ganciclovir. Am J Kidney Dis 2005;45:E12-E15.

12 Ariceta G, Besbas N, Johnson S, Karpman D, Landau D, Licht C, Loirat C, Pecoraro C Taylor CM, Van de Kar N, Vandewalle J, Zimmerhackl LB, European Paediatric Study Group for HUS: Guideline for the investigation and initial therapy of diarrheanegative hemolytic uremic syndrome. Pediatr Nephrol 2009;24:687-696.
13 Besbas N, Karpman D, Landau D, Loirat C, Proesmans W, Remuzzi G, Rizzoni G, Taylor CM, Van de Kar N, Zimmerhackl LB, European Paediatric Research Group for HUS: A classification of hemolytic uremic syndrome and thrombotic thrombocytopenic purpura and related disorders. Kidney Int 2006;70: 423-431.

14 Jeejeebhoy FM, Zaltzman JS: Thrombotic microangiopathy in association with cytomegalovirus infection in a renal transplant patient: a new treatment strategy. Transplantation 1998;65:1645-1648.

15 Noël C, Saunier P, Hazzan M, Pruvot FR, Dracon $\mathrm{M}$, Jude B, Lelièvre G: Incidence and clinical profile of microvascular complications in renal allografted patients treated with cyclosporine. Ann Med Interne 1992; 143(suppl 1):33-36

16 Crough T, Khanna R: Immunobiology of human cytomegalovirus: from bench to bedside. Clin Microbiol Rev 2009;22:76-98.

17 Kotton CN, Kumar D, Caliendo AM, Åsberg A, Chou S, Snydman DR, Allen U, Humar A, Transplantation Society International CMV Consensus Group: International consensus guidelines on the management of cytomegalovirus in solid organ transplantation. Transplantation 2010;89:779-794 